\title{
O LEVIRATO NAS LEIS MÉDIO-ASSÍRIAS
}

THE LEVIRATE MARRIAGE IN MIDDLE ASSYRIAN LAWS

Alessandro Hirata*

Resumo:

O levirato é conhecido no direito hebraico, sendo ainda mencionado no Antigo Testamento. Um pressuposto para a ocorrência do levirato é o falecimento do irmão sem filhos, ou seja, sem herdeiros, levando a terra a uma situação de risco. A fim de proteger esse imóvel, além de dar à viúva uma posição social assegurada, o irmão, que fosse maior de idade durante a vida do irmão morto, casava-se com a cunhada. Na doutrina, é mencionada uma origem assíria para o levirato. Objetivo desse trabalho é analisar as determinações das Leis Médio-Assírias que possam ter alguma importância para o tratamento do levirato.

Palavras-chave: Levirato. Leis Médio-Assírias. Propriedade.

\begin{abstract}
:
The levirate marriage is known in Hebrew law and even mentioned in the Old Testament. A prerequisite for the occurrence of the levirate marriage is the death of a brother without children, or without heirs, risking the property unit. In order to protect this property, in addition to the assurance of a social position to the widow, his brother, who was an adult during the life of the dead brother, should marry to his sister-in-law. In the literature, it is mentioned for the levirate marriage an Assyrian origin. The purpose of this work is to analyze the provisions of Middle Assyrian Laws that may have some relevance for the treatment of the levirate marriage.
\end{abstract}

Keywords: Levirate marriage. Middle Assyrian Laws. Property.

1. Introdução

1.1. O levirato

O conceito do levirato, ${ }^{1}$ que deriva etimologicamente do termo latino "levir" (cunhado), é conhecido também no direito hebraico, sendo ainda mencionado no

\footnotetext{
Professor Associado da Faculdade de Direito de Ribeirão Preto da Universidade de São Paulo e Doutor em Direito pela Ludwig-Maximilians-Universität München (Alemanha).

1 Cf., dentre outros, sobre literatura sobre o levirato em geral: SKAIST, A. Levirat. In: EBELING, E.; MEISSNER, B. Reallexikon der Assyriologie und Vorderasiatischen Archäologie VI. Berlin-New York, 1980-1983. p. 605 e ss.; CARDASCIA, G. L'adoption matrimoniale à Babylone et à Nuzi. Revue Historique de Droit Français et Etranger, v. 37, p. 1-16, 1959; KOSCHAKER, P. Zum Levirat nach hethitischem Recht. Revue Hittite et Asianique, v. 10, p. 77-89, 1933. Sobre o levirato nas Leis Médio-Assírias, cf.: MEISSNER, B. Das altassyrische Schwagerehe. Orientalistische Litteraturzeitung, v. 23, n. 11/12, p. 246-248, 1920; PEISER, F. E. Zur altassyrischen Schwagerehe. Orientalistische Litteraturzeitung, v. 23, n. 11/12, p. 248249, 1920; KOSCHAKER, P. Quellenkritische Untersuchungen zu den ,, altassyrischen Gesetzen”. Leipzig: J. C. Hinrichs, 1921. p. 48-56; DRIVER, G. R.; MILES, J. C. The assyrian laws. Oxford: Clarendon Press,
} 
Antigo Testamento. ${ }^{2}$ Um pressuposto para a ocorrência do levirato é o falecimento do irmão sem filhos, ou seja, sem herdeiros, levando a terra - como dádiva divina à família a uma situação de risco. A fim de proteger esse imóvel, além de dar à viúva uma posição social assegurada, o irmão, que fosse maior de idade durante a vida do irmão morto, casava-se com a cunhada. Se o irmão mais próximo não estivesse apto a se casar com a sua cunhada, tal dever passava para o próximo irmão. Se o único irmão possível ainda não tivesse capacidade para se casar, a viúva precisaria esperar até que ele se tornasse maior de idade para fazê-lo. O objetivo desse casamento era produzir um herdeiro masculino, que receberia a posição jurídica e social do marido morto, sendo considerado seu filho juridicamente. $\mathrm{O}$ casamento entre cunhados não era permitido no direito hebraico quando já existiam filhos do primeiro casamento.

$\mathrm{Na}$ doutrina, ${ }^{3}$ é mencionada uma origem assíria para o levirato. Objetivo desse trabalho é analisar as determinações das Leis Médio-Assírias que possam ter alguma importância para o tratamento do levirato. Logicamente, não é de se esperar que se encontre nas Leis Médio-Assírias essa conhecida figura do direito hebraico. Metodologicamente, procura-se a fatispécie em que uma viúva deva se casar com o seu cunhado. ${ }^{4}$

\subsection{As Leis Médio-Assírias}

As Leis Médio-Assírias5 (tabuleta “A”, com 59 artigos) são originárias da cidade de Assur, ao norte da Mesopotâmia, tendo sido elaboradas por volta de 1.400 a.C. A cópia que chegou até nós não é uma versão oficial, mas sim uma compilação particular de

1935. p. 240-250; VAN PRAAG, A. Droit matrimonial assyro-babylonien. Amsterdam: Noord-Hollandsche Uitgevers Maatschappij, 1945. p. 115-127; E. OTTO, E. Biblische Altersversorgung im altorientalischen Rechtsvergleich. Zeitschrift für Altorientalische und Biblische Rechtsgeschichte, n. 1, p. 83-110, 1995. p. 104, e BORGER, R. Die mittelassyrischen Gesetze. Texte aus der Umwelt des Alten Testaments I, Gütersloh, n. 1, p. $80-92,1982$.

2 Gênesis 38, Deuteronômio 25:5-10 e Rute 3-4.

3 Cf., dentre outros, KOSCHAKER, P. Quellenkritische Untersuchungen zu den „, altassyrischen Gesetzen“. Leipzig: J. C. Hinrichs, 1921. p. 48-56.

4 Cf. sobre a metodologia de pesquisa nos direitos de escrita cuneiforme: HIRATA, A. Dogmática como instrumento metodológico na pesquisa histórica do direito. In: RODRIGUEZ, José Rodrigo; COSTA, Carlos Eduardo Batalha da Silva e; BARBOSA, Samuel Rodrigues. (Org.). Nas fronteiras do formalismo: a função social da dogmática jurídica hoje. São Paulo: Saraiva, 2010. p. 63-72.

5 Tabuletas A até O (exceto J). Edições: SCHRÖDER, O. Keilschrifttexte aus Assur verschiedenen Inhalts. Leipzig: J. C. Hinrichs'sche Buchhandlung, 1920; DRIVER, G. R.; MILES, J. C. The assyrian laws. Oxford: Clarendon Press, 1935. p. 381-453, cf. também WEIDNER, E. Das Alter der mittelassyrischen Gesetzestexte. Archiv für Orientforschung, v. 12, p. 46-54, 1937-1939. p. 46-54. Traduções: EHELOLF, H. Ein altassyrisches Rechtsbuch. Berlin: Curtius, 1922; BORGER, R. Die mittelassyrischen Gesetze. Texte aus der Umwelt des Alten Testaments I, Gütersloh, n. 1, p. 80-92, 1982. p. 80-92; CARDASCIA, G. Les lois assyriennes. Paris: Éditions du Cerf, 1969. (Tabuletas A até O), e SAPORETTI, C. Le leggi medioassire. Malibu: Undena Publications, 1979. Nova literatura, cf. LAFONT, S. Middle Assyrian period. In: WESTBROOK, R. A history of ancient near eastern law II. Leiden-Boston: Brill, 2003. p. 521-563. 
dispositivos legais. A tabuleta "A" contém determinações sobre as mulheres, o que levou P. Koschaker ${ }^{6}$ a chamar essas normas de "Rechtsspiegel für Frauen", ou seja, "Espelho do direito para mulheres".

A situação jurídica da mulher, aqui documentada, pode ser caracterizada, de um modo geral, como desprivilegiada e profundamente dependente do pai ou do marido, conforme sua situação matrimonial. Além disso, os dispositivos legais são, individualmente, de difícil compreensão. Frequentemente parecem ser decisões judiciais generalizadas de modo bastante lacunoso, por meio da inserção de comentários, técnica que possivelmente distorceu o sentido das decisões. G. Cardascia, ${ }^{7}$ que analisou cuidadosamente esses textos, especialmente em seu livro "Les lois assyriennes", chama essas leis de "gabinete de horrores" da história do direito, em virtude da gravidade e, muitas vezes, crueldade de suas penas.

A seguir, serão tratadas as determinações legais das Leis Médio-Assírias, que cuidam do fenômeno do levirato: arts. 30, 31, 43, 33 e 46.

2. Possíveis indícios para o levirato nas Leis Médio-Assírias: arts. 30, 31, 43, 33 e 46

A busca aqui se deu nas determinações legais das Leis Médio-Assírias, na procura de fatispécies nas quais a morte do marido ou da esposa levou a um casamento dentro da mesma família. Tal ocorrência pode ser observada nos arts. 30, 31, 43, 33 e 46.

Art. 30

Col. IV, 20 šum-ma a-bu a-na É e-me ša DUMU-šu

21 bi-ib-la it-ta-bal iz-zi-bi-el

22 SAL a-na DUMU-šu la-a ta-ad-na-at

23 ù DUMU-šu ša-ni-ú ša DAM-šu

24 i-na É a-bi-ša us-bu-tu-ú-ni

25 me-e-it DAM ${ }^{\text {at }}$ DUMU-šu me-e-te

26 a-na DUMU-šu ša-na-i-e

27 ša a-na É e-me-šu iz-bi-lu-ú-ni

28 a-na a-hu-zi-te i-id-dan-ši

29 šum-ma EN DUMU.SAL ša zu-bu-ul-la-a

30 im-ta-ah-hu-ru-ú-ni

31 DUMU.SAL-su a-na ta-da-a-ni

${ }^{6}$ KOSCHAKER, P. Quellenkritische Untersuchungen zu den „,altassyrischen Gesetzen”. Leipzig: J. C. Hinrichs, 1921. p. 82.

7 CARDASCIA, G. Les valeurs morales dans le droit Assyrien. Acta Antiqua Academiae Scientiarum Hungaricae XXII, Budapest, n. 1-4, 1974. p. 371. 
32 la-a i-ma-ag-gu-ur

33 hya-di-ma a-bu ša-a zu-bu-ul-la-a

34 iz-bi-lu-ú-ni kal-la-a-su

35 i-lak-ki-a a-na DUMU-šu id-dan

36 ù Ja-di-ma am-mar iz-bi-lu-ú-ni

37 AN.NA șar-pa GUŠKIN ša la a-ka-a-li

38 SAG.DU-ma i-lak-ki

39 a-na ša a-ka-li la-a i-qar-ri-ib

Art. 30: ${ }^{20}$ Se um pai, na casa do sogro de seu filho, ${ }^{21}$ entrega o preço da noiva, ${ }^{22}(\mathrm{e})$ a mulher não é entregue ao seu filho, ${ }^{23} \mathrm{e}$ um outro filho, cuja noiva ${ }^{24}$ more na casa do seu pai, ${ }^{25}$ morre, deve ele dar a noiva de seu filho morto ${ }^{26}$ ao seu segundo filho, ${ }^{27}$ para quem ele (o pai) entregou (o preço da noiva), ${ }^{28} \mathrm{em}$ casamento. ${ }^{29} \mathrm{Se}$ o senhor (pai) da filha, que o preço da noiva ${ }^{30}$ tinha aceitado, ${ }^{31}$ com a entrega (para o casamento) de sua filha ${ }^{32}$ não estiver de acordo, ${ }^{33}$ pode ele, se ele quiser, o pai, que o preço da noiva ${ }^{34} \mathrm{entregou}$, pegar sua nora ${ }^{35} \mathrm{e}$ dar ao seu filho. ${ }^{36} \mathrm{Se}$ ele quiser, entretanto, ele também pode retomar tudo, o que ele tinha entregue, ${ }^{37}$ estanho, prata, ouro, e tudo que não for comestível, ${ }^{38}$ apenas aquilo ${ }^{39}$ que for comestível, ele não pode tocar.

$\mathrm{O}$ art. 30 assegura o direito a um pai, que pagou o "preço da noiva", ${ }^{8}$ de dar em casamento a um outro filho seu, a sua nora que ficou viúva. Ou seja, se já tinha pago o preço da noiva, pode o pai entregá-la a um filho, ainda que diverso daquele que se originalmente pretendia. Vale lembrar que esse direito do pai também existe mesmo se a nora ainda more na casa de seu próprio pai e mesmo se o outro filho já tem uma noiva (mas desde que essa noiva ainda more na casa do seu pai). Além disso, cabe mencionar que o pai também pode retomar o "preço da noiva". O mesmo art. 30 ainda determina que o pai pode tomar a sua nora e dar em casamento ao seu filho, mesmo contra a vontade do próprio pai da nora.

Para o melhor entendimento, entretanto, deve-se analisar o artigo seguinte das Leis Médio-Assírias:

Art. 31

Col. IV, 40 šum-ma LÚ a-na É e-me-šu

41 zu-bu-ul-la-a iz-bil ù DAM-su

\footnotetext{
8 O preço da noiva é uma figura jurídica que aparece nas fontes desde o Código de Hammurabi (cf., por exemplo, arts. 159 a 161 do Código de Hammurabi). Trata-se do valor pago pelo noivo (ou por sua família), a fim de realizar um casamento. Trata-se do correspondente ao dote, que é prestado pela noiva ou por sua família. Cf. LAFONT, S. Middle Assyrian period. In: WESTBROOK, R. A history of ancient near eastern law II. Leiden-Boston: Brill, 2003. p. 521-563. p. 535-536.
} 
42 me-ta-at DUMU.SAL.MEŠ e-mi-šu

43 i-ba-áš-ši ḩa-di-ma e-mu

44 DUMU.SAL e-mi-šu ki-i DAM-šu me-it-te

45 ih-hha-az ù ha-di-ma

46 KÙ.BABBAR ša id-di-nu-ú-ni i-lak-ki

47 lu-ú Š̉ ${ }^{a m}$ lu-ú LU.MEŠ lu-ú min-ma

48 ša a-ka-li la-a id-du-nu-ni-šu

49 KÙ.BABBAR-ma i-mah-hya-ar

Art. 31: ${ }^{40}$ Se um homem leva até a casa de seu sogro ${ }^{41}$ o preço da noiva e a sua noiva ${ }^{42}$ depois vem a falecer, (e outras) filhas do seu sogro ${ }^{43}$ ainda estão disponíveis, pode ele, quem o sogro quiser, ${ }^{44}$ com uma (outra) filha do seu sogro, no lugar da noiva falecida, ${ }^{45}$ se casar. Ele pode também, contudo, se ele quiser, ${ }^{46}$ retomar a prata, que ele tinha dado. ${ }^{47}$ Grãos, ovelhas e tudo mais ${ }^{48}$ que seja comestível, não precisa ser devolvido a ele, ${ }^{49}$ ele receberá apenas a prata.

Trata-se, aqui, de uma determinação semelhante ao art. 30, que se refere ao caso de morte da noiva. O homem, que havia entregado o preço da noiva para o seu futuro sogro, pode casar-se com uma outra filha do sogro, se este estiver de acordo. Por outro lado, caso seja de seu interesse, pode ele retomar o preço da noiva pago, abrindo mão de se casar com umas das irmãs da falecida noiva.

\section{Art. 43}

Col. VI, 19 šum-ma LÚ lu-ú IÀ.GIŠ a-na SAG.DU it-bu-uk

20 lu-ú hu-ru-up-pa-a-te ú-bil

21 DUMU ša DAM ${ }^{\text {ta }}$ ú-di-ú-ni-šu-ni

22 lu-ú me-e-it iu-ú in-na-bi-it

23 i-na DUMU.MEŠšsu ri-ḩa-a-te

24 iš-tu MUH DUMU GAL ${ }^{\mathrm{e}}$ a-di MUH DUMU

25 și-ih-ri ša-a IO MU.MEŠ-šu-ni

26 a-na ša ha-di-ú-ni i-id-dan

27 šum-ma a-bu me-it ù DUMU ša DAM ${ }^{\text {ta }}$

28 ú-ud-di-É-ni-Xu-ni me-e-it-ma

29 DUMU DUMU ${ }^{e}$ me-e-te ša IO MU.MEŠ-šu-ni

30 i-ba-áš-ši ih̆-ḩa-az-ma

31 šum-ma a-na qa-a-at IO MU.MES

32 DUMU.MEŠ DUMU' și-ih̆-hii-ru

33 a-bu ša DUMU.SAL ha-di-ma DUMU.SAL-su id-dan

34 ú Ja-di-i-ma tu-ur-ta 
35 a-na mi-it-ḩa-ar ú-ta-ar

36 šum-ma DUMU la-áš-šu am-mar im-ḩu-ru-ú-ni

37 ZÁ ù mi-im-ma Xa la a-ka-li

38 SAG.DU-ma ú-ta-ar

39 ù Xa-a a-ka-li la-a ú-tar

Art. 43: ${ }^{19}$ Se um homem joga óleo na cabeça (da filha de um outro) ${ }^{20}$ ou traz um presente de casamento (?), ${ }^{21}$ (e) o filho, a quem foi destinada a noiva, ${ }^{22}$ morre ou foge, ${ }^{23}$ pode ele (o pai) dá-la a um de seus filhos restantes, ${ }^{24}$ do mais velho ao ${ }^{25}$ mais novo filho, que deve ter (pelo menos) dez anos de idade, ${ }^{26}$ a quem ele quiser. ${ }^{27} \mathrm{Se}$ o pai está morto e também o filho, a quem a noiva ${ }^{28}$ está destinada, também morre, ${ }^{29} \mathrm{e}$ existe um filho do filho morto, que tem (pelo menos) dez anos de idade, ${ }^{30}$ ele deve casar com ela. ${ }^{31}$ Se eles forem mais jovens do que dez anos de idade, ${ }^{32}$ os filhos do filho (morto), ${ }^{33}$ pode o pai da filha, se ele quiser, entregar a sua filha, ${ }^{34} \mathrm{ou}$, se ele quiser, ${ }^{35}$ conforme (o que ele tinha recebido), cancelar tudo. ${ }^{36} \mathrm{Se}$, entretanto, não houver nenhum filho disponível, ele deve, tudo aquilo que ele recebeu, ${ }^{37}$ pedras (preciosas) e tudo aquilo, que não for comestível, ${ }^{38}$ devolver. ${ }^{39}$ Aquilo que for comestível, ele não precisa devolver.

Aqui é tratada a fatispécie em que uma mulher é aceita como noiva por meio de um ritual (jogar óleo sobre a sua cabeça ${ }^{9}$ ), e seu noivo vem a falecer. Para tal caso, são apresentadas algumas soluções possíveis: ${ }^{10}$ o pai do morto pode dar em casamento a prometida noiva para um outro filho seu, desde que este tenha mais de dez anos de idade. Além disso, a noiva deve casar com um filho do noivo que morreu, se este tiver pelo menos dez anos de idade e se o pai do morto também já tenha morrido. ${ }^{11}$ Caso, entretanto, não haja nenhum filho do morto que tenha mais de dez anos de idade, pode o pai da noiva, novamente, determinar o seu destino: ele pode entregá-la a um filho - menor de dez anos de idade - do falecido noivo, na esperança de que ele chegue à idade necessária (maior

9 O significado do termo "huruppatu" é bastante controverso. Trata-se, contudo de uma parte do ritual (1. 20). Na tradução de DRIVER, G. R.; MILES, J. C. The assyrian laws. Oxford: Clarendon Press, 1935. p. 411; aparece como "wedding-gifts". Mas SAPORETTI, C. Le leggi medioassire. Malibu: Undena Publications, 1979. p. 73, traduz como "banchetto die fidanzamento". Já para EHELOLF, H. Ein altassyrisches Rechtsbuch. Berlin: Curtius, 1922. p. 37; o termo significaria "Bronzeschüsseln", apesar de ressaltar, que se trata de uma palavra controversa. Cf. também KOSCHAKER, P. Quellenkritische Untersuchungen zu den „,altassyrischen Gesetzen”. Leipzig: J. C. Hinrichs, 1921. p. 51.

10 Cf. também C. SAPORETTI, C. Le leggi medioassire. Malibu: Undena Publications, 1979. p. 73.

11 KOSCHAKER, P. Quellenkritische Untersuchungen zu den ,altassyrischen Gesetzen”. Leipzig: J. C. Hinrichs, 1921. p. 49, nt. 3, entre, que o trecho entre as linhas 27 e 35 foi incluído posteriormente no texto. Provavelmente, tratava-se de um caso prático, que foi colocado por aquele que escreveu essa tabuleta com as leis. 
de dez anos), ou ele deve devolver tudo o que recebeu como "preço da noiva" e desfazer toda a operação. ${ }^{12}$

Art. 33

Col. IV, 56 [šum-ma] SAL i-na É [a]-bi-ša-ma us-bat

57 [mu]-us-sa [me-e]-it ${ }^{1}$ ù DUMU.[MEŠ-ša]

58 [i-ba]-áš-ši ${ }^{\mathrm{I}}[\ldots]$

59-64 [Lücke]

65 ù Ja-[di]-ma a-na e-mi-Xa

66 aa-na a-hu-[zi]-te i-id-dan-ši

67 šum-ma mu-[us]-sa ù e-mu-ša

68 me-e-tu-[ma] ù DUMU-ša áš-šu

69 al-ma-at-tu ši-i-it

70 a-šar ḩa-di-tu-ú-ni ta-al-lak

Art. 33: ${ }^{56}[\mathrm{Se}]$ uma mulher mora na casa de seu pai, ${ }^{57} \mathrm{e}$ o seu noivo vem a falecer e filhos ${ }^{58}$ estão disponíveis [...] [lacuna ${ }^{65} \mathrm{e}[\ldots]$ ele pode entregar ela ao sogro dela ${ }^{66} \mathrm{em}$ casamento. ${ }^{67} \mathrm{Se}$ o seu noivo e o seu sogro ${ }^{68} \mathrm{vem}$ a falecer e ela não tem nenhum filho, ${ }^{69}$ então ela é viúva ${ }^{70}$ e por ir, para onde ela quiser.

Infelizmente, o início deste trecho de texto está tão fragmentado, que não se pode reconstruí-lo. Na literatura secundária, ${ }^{13}$ adota-se a reconstrução sugerida por Driver e Miles, ${ }^{14}$ segundo quem se trata de um tipo de levirato no caso de uma viúva. Com base nessas possíveis reconstruções do texto e, especialmente, levando em conta a última frase que chegou completa até nós, pode-se concluir que, existindo um membro da família do noivo morto, a viúva pode contrair núpcias, permanecendo na família do noivo. Apenas para os casos em que não exista essa possibilidade, ela será considerada viúva e pode se desligar da família.

$\underline{\text { Art. } 46}$

Col. VI, 89-108 [...]

109 ù Xum-ma i-na DUMU.MEŠ mu-ti-ša-a-ma

110 ša-a e-ḩu-zu-ši-ni i-[ba-aš]-ši

\footnotetext{
12 Cabe ressaltar também que, como já levantado por SAPORETTI, C. Le leggi medioassire. Malibu: Undena Publications, 1979. p. 74, caso o pai da noiva devolva o preço da noiva, mas o morto não deixou nenhum filho, devem os herdeiros do morto receber tal preço da noiva devolvido.

13 Cf. CARDASCIA, G. Les lois assyriennes. Paris: Éditions du Cerf, 1969. p. 178.

14 DRIVER, G. R.; MILES, J. C. The assyrian laws. Oxford: Clarendon Press, 1935. p. 400.
} 


\section{1 [a-ḩi-za-aš]-ša-ma [ú-Xa-kal-ši]}

\section{2 [DUMU.MEŠ-ša-ma la]-a ú-Xa-ku-lu-ši}

Art. 46: ${ }^{109} \mathrm{Se}$, entretanto, dentre os filhos do noivo, ${ }^{110}$ há algum deles, que queira casar com ela, ele deve esposá-la, ${ }^{111}$ então, deve esse, que casou com ela, [sustentála]. ${ }^{112}$ [Os seus filhos] não precisam ser sustentados por eles.

No art. 46, é interessante para o tratamento do levirato apenas a última parte, aqui reproduzida. Trata-se do caso de uma viúva que deve se casar com o filho do seu falecido noivo. Logicamente, trata-se de um filho do primeiro casamento do morto. Nesse artigo é, então, diferenciada a primeira (panitu) da segunda esposa (urkittu). ${ }^{15}$

As determinações legais contidas na tabuleta "A" são bastante próximas ao levirato, mesmo que não se tenha a mesma estrutura dogmática do levirato bíblico. Alguns aspectos jurídicos dessas regras das Leis Médio-Assírias merecem uma atenção especial, uma vez que se trata do emprego do chamado "Kaufehe", ou seja, "casamento compra". Desse modo, trata-se de um casamento com características semelhantes à compra e venda, tendo a mulher uma posição subordinada ao homem. ${ }^{16}$ Nos arts. 30 e 21 das Leis MédioAssírias, o levirato aparece no momento do noivado e ainda pode ser identificado como sendo bilateral. ${ }^{17}$ Pode-se entender a respeito da bilateralidade do levirato que tanto a viúva deve esposar o irmão do morto, quanto o viúvo deve casar-se com a irmã da esposa morta. ${ }^{18}$ Vale ressaltar, que o levirato do irmão é um direito. O pai do morto, que tinha entregado o preço da noiva, tem o direito de entregar a mulher ao irmão do noivo falecido. Diferentemente em relação ao levirato da irmã: trata-se de um direito do noivo, no art. 31, receber a irmã da noiva falecida, uma vez que ele pode, alternativamente, pleitear o preço da noiva de volta. Ele precisa, contudo, do consentimento do pai da noiva, que, segundo o art. 30, é dispensável para o levirato do irmão.

Ainda em relação aos arts. 30 e 31 extraem-se aspectos referentes à natureza jurídica do noivado. ${ }^{19}$ Deve-se entender que o aperfeiçoamento do matrimônio apenas se daria com entrega da mulher ao seu noivo ou ao pai deste. Além disso, cabe ressaltar que já com o pagamento do "preço da noiva", a noiva passa ao poder familiar do noivo (ou do

15 Cf. SAPORETTI, C. Le leggi medioassire. Malibu: Undena Publications, 1979. p. 80.

16 Apesar de ser polêmica tal expressão nos direitos de escrita cuneiforme, é possível fazer tal aproximação entre o casamento e o contrato de compra e venda. No direito romano, cabe lembrar a figura da "coemptio" como celebração do casamento cum manu, o que deu origem ao termo "Kaufehe". Cf., sobre a coemptio, dentre outros: KASER, M. Das römische Privatrecht I. München: [s.n.], 1971. p. 77-78.

17 KOSCHAKER, P. Quellenkritische Untersuchungen zu den „,altassyrischen Gesetzen”. Leipzig: J. C. Hinrichs, 1921. p. 48.

18 KOHLER, J. Das recht der Chins. Zeitschrift für Vergleichende Rechtswissenschaft, v. 6, 1886. p. 188.

19 Cf. KOSCHAKER, P. Quellenkritische Untersuchungen zu den ,altassyrischen Gesetzen”. Leipzig: J. C. Hinrichs, 1921. p. 51. 
seu pai), mesmo que ela ainda more na casa de seu pai. O "preço da noiva", geralmente pago pelo pai do noivo, tem a finalidade de fazer com que a noiva seja entregue em casamento ao seu filho. Se tal filho vier a falecer, pode o pai, mesmo assim, atingir o seu objetivo, caso ele ainda tenha outros filhos, que possam esposá-la. Por conseguinte, podese identificar uma finalidade no levirato: evitar a devolução do preço da noiva, por meio do casamento da noiva com um outro membro da família do noivo falecido. Por isso, em virtude do funcionamento do "preço da noiva", é bastante plausível tratar o matrimônio nas Leis Médio-Assírias como uma forma de "Kaufehe".

Mesmo se o pai que pagou o preço da noiva vem a falecer, a mulher é tratada como em um "Kaufehe". Se o pai morre, a mulher estará sob o pátrio poder do seu filho, ou seja, seu noivo. Se ele também vem a falecer, deve a mulher ser entregue a um de seus filhos do primeiro casamento, que esteja disponível, segundo o art. 43 das Leis MédioAssírias. P. Koschaker ${ }^{20}$ entende, por isso, que se trata de uma espécie de "herança" da noiva ou da viúva. Afinal, se o noivo falece e seu pai ainda vive, a noiva permanece sob o poder do pai do morto por meio da herança e em virtude do levirato. Consequentemente, esse pai pode dar em casamento a noiva a um irmão ou filho do noivo morto.

Relevante também é o art. 43, que apresenta um princípio de outra cultura jurídica: ${ }^{21}$ a noiva pode ser dada em casamento para um filho do primeiro casamento do falecido noivo. Nas Leis Médio-Assírias, entretanto, esse princípio é combinado com a não utilização do levirato da viúva: ${ }^{22} \mathrm{Se}$ o pai do noivo morto já é também falecido, ninguém tem o direito de entregar em casamento a noiva do morto a um de seus irmãos. Por isso, ela deve se casar com um dos filhos do morto. ${ }^{23}$ Nesse sentido, o texto art. 33 é reconstruído por G. Driver, J. Miles ${ }^{24}$ e C. Saporetti. ${ }^{25}$ Desse modo, a figura típica de levirato presente em outras culturas históricas não tem exatamente o mesmo tratamento nas Leis Médio-Assírias, uma vez que a viúva não será dada em casamento para um irmão do morto, caso o seu pai também já fosse falecido. Se o morto não tivesse filhos, ela seria declarada viúva em sentido estrito (almattu) e poderia determinar o seu modo de vida como quisesse (art. 33). ${ }^{26}$

20 KOSCHAKER, P. Quellenkritische Untersuchungen zu den „, altassyrischen Gesetzen”. Leipzig: J. C. Hinrichs, 1921. p. 53.

${ }^{21}$ KOSCHAKER, P. Quellenkritische Untersuchungen zu den „, altassyrischen Gesetzen”. Leipzig: J. C. Hinrichs, 1921. p. 49, nt. 2.

22 Cf. KOSCHAKER, P. Quellenkritische Untersuchungen zu den ,,altassyrischen Gesetzen”. Leipzig: J. C. Hinrichs, 1921. p. 49.

23 Cf. SAPORETTI, C. Le leggi medioassire. Malibu: Undena Publications, 1979. p. 73.

24 DRIVER, G. R.; MILES, J. C. The assyrian laws. Oxford: Clarendon Press, 1935. p. 400.

25 SAPORETTI, C. Le leggi medioassire. Malibu: Undena Publications, 1979. p. 61.

26 VAN PRAAG, A. Droit matrimonial assyro-babylonien. Amsterdam: Noord-Hollandsche Uitgevers Maatschappij, 1945. p. 120, defende a opinião de que o filho do morto, no art. 33, receberia em casamento a sua madrasta, como parte de sua herança. Ele não seria, entretanto, um levir. 


\section{Conclusões}

Em suma, após a análise dos artigos relacionados ao fenômeno do levirato nas Leis Médio-Assírias, pode-se concluir ser possível identificar tal figura nesse documento legal, mesmo que com características diversas do modelo hebraico, que se desenvolveu posteriormente. Assim, pode-se falar em um levirato do período médioassírio.

Não se quer dizer aqui, por outro lado, que o levirato bíblico deriva do então existente na Assíria. Tais possibilidades de transferências de conhecimentos jurídicos apesar de possíveis - são extremamente difíceis de serem comprovadas. ${ }^{27}$ Ademais, é plausível que se tratem de desenvolvimentos paralelos de figuras semelhantes, em virtude de uma organização socioeconômica também parecida.

Além disso, é preciso ressaltar que o levirato nas Leis Médio-Assírias parece ser uma consequência jurídica do "Kaufehe", ou seja, do "casamento-compra". Desse modo, é fundamental o aspecto patrimonial do casamento (e do levirato). Ou seja, é um desdobramento dos direitos relacionados ao pagamento do "preço da noiva", demonstrando estar mais relacionado ao caráter patrimonial do que a aspectos culturais da sociedade médio-assíria.

Ribeirão Preto, março de 2015.

\section{Referências}

BORGER, R. Die mittelassyrischen Gesetze. Texte aus der Umwelt des Alten Testaments I, Gütersloh, n. 1, p. 80-92, 1982.

CARDASCIA, G. L'adoption matrimoniale à Babylone et à Nuzi. Revue Historique de Droit Français et Etranger, v. 37, p. 1-16, 1959.

CARDASCIA, G. Les lois assyriennes. Paris: Éditions du Cerf, 1969.

CARDASCIA, G. Les valeurs morales dans le droit Assyrien. Acta Antiqua Academiae Scientiarum Hungaricae XXII, Budapest, n. 1-4, p. 371, 1974.

DRIVER, G. R.; MILES, J. C. The assyrian laws. Oxford: Clarendon Press, 1935.

\footnotetext{
27 Sobre a transferência de direito sob a perspectiva de direito comparado histórico no contexto do direito romano, cf. HIRATA, A. Die Generalklausel zur Hybris in den alexandrinischen Dikaiomata. Zeitschrift der Savigny-Stiftung für Rechtsgeschichte, v. 125, p. 675-681, 2008 e HIRATA, A. Die alexandrinischen Dikaiomata als Quelle der historischen Rechtsvergleichung. In: LANG, M.; BARTA, H.; ROLLINGER, R. Staatsverträge, Völkerrecht und Diplomatie im Alten Orient und in der griechisch-römischen Antike. Wiesbaden: Harrassowitz, 2010. p. 39-50.
} 
EHELOLF, H. Ein altassyrisches Rechtsbuch. Berlin: Curtius, 1922.

HIRATA, A. Die alexandrinischen Dikaiomata als Quelle der historischen Rechtsvergleichung. In: LANG, M.; BARTA, H.; ROLLINGER, R. Staatsverträge, Völkerrecht und Diplomatie im Alten Orient und in der griechisch-römischen Antike. Wiesbaden: Harrassowitz, 2010. p. 39-50.

HIRATA, A. Die Generalklausel zur Hybris in den alexandrinischen Dikaiomata. Zeitschrift der Savigny-Stiftung für Rechtsgeschichte, v. 125, p. 675-681, 2008.

HIRATA, A. Dogmática como instrumento metodológico na pesquisa histórica do direito. In: RODRIGUEZ, José Rodrigo; COSTA, Carlos Eduardo Batalha da Silva e; BARBOSA, Samuel Rodrigues. (Org.). Nas fronteiras do formalismo: a função social da dogmática jurídica hoje. São Paulo: Saraiva, 2010. p. 63-72.

KASER, M. Das römische Privatrecht I. München: [s.n.], 1971.

KOHLER, J. Das recht der Chins. Zeitschrift für Vergleichende Rechtswissenschaft, v. 6, 1886.

KOSCHAKER, P. Quellenkritische Untersuchungen zu den ,altassyrischen Gesetzen”. Leipzig: J. C. Hinrichs, 1921. p. 48-56.

KOSCHAKER, P. Zum Levirat nach hethitischem Recht. Revue Hittite et Asianique, v. 10, p. 77-89, 1933.

LAFONT, S. Middle Assyrian period. In: WESTBROOK, R. A history of ancient near eastern law II. Leiden-Boston: Brill, 2003. p. 521-563.

MEISSNER, B. Das altassyrische Schwagerehe. Orientalistische Litteraturzeitung, v. 23, n. 11/12, p. 246-248, 1920.

OTTO, E. Biblische Altersversorgung im altorientalischen Rechtsvergleich. Zeitschrift für Altorientalische und Biblische Rechtsgeschichte, n. 1, p. 83-110, 1995.

PEISER, F. E. Zur altassyrischen Schwagerehe. Orientalistische Litteraturzeitung, v. 23, n. 11/12, p. $248-249,1920$.

SAPORETTI, C. Le leggi medioassire. Malibu: Undena Publications, 1979.

SCHRÖDER, O. Keilschrifttexte aus Assur verschiedenen Inhalts. Leipzig: J. C. Hinrichs'sche Buchhandlung, 1920.

SKAIST, A. Levirat. In: EBELING, E.; MEISSNER, B. Reallexikon der Assyriologie und Vorderasiatischen Archäologie VI. Berlin-New York, 1980-1983. p. 605 e ss.

VAN PRAAG, A. Droit matrimonial assyro-babylonien. Amsterdam: Noord-Hollandsche Uitgevers Maatschappij, 1945.

WEIDNER, E. Das Alter der mittelassyrischen Gesetzestexte. Archiv für Orientforschung, v. 12, p. 46-54, 1937-1939. 
